Australian Journal of

Educational Technology

\title{
Multimedia reporting in science problem solving
}

\author{
Barry M. Harper, John G. Hedberg, \\ Robert J. Wright and Robert M. Corderoy \\ Faculty of Education \\ University of Wollongong \\ NSW, Australia \\ Email b.harper@uow.edu.au
}

\begin{abstract}
The increasing availability of CD ROM based interactive multimedia packages to support learning in science classrooms offers science teachers new pedagogical opportunities for student-centred and cooperative learning. However, many of the current products do not make full use of the existing technology in schools and even when they do they tend to constrain the student to a very limited view of information and how it can be used as part of student reporting of inquiry projects.

Interactivity in many packages has been limited to "point and click" rather than employing instructional strategies that immerse and challenge students. The Interactive Multimedia Learning Laboratory at the University of Wollongong has developed two interactive multimedia packages designed for Australian schools that not only attempt to develop problem solving skills but also allow students to express their ideas with different forms of representation in their reports.
\end{abstract}

Investigating Lake Iluka, based on the ecology of a coastal lake environment uses a text based notebook which allows the student to select text and edit it into their report on their problem investigation A second package, Exploring the Nardoo, based on water management issues extends the concept to include multimedia elements in the student's notebook. The evaluation of both packages has examined the ability of students to express themselves in text together with static and dynamic aural and visual forms. This paper also reports on improvement of scientific understanding and improved problem' reporting based on metacognitive supports included in these interactive multimedia packages, especially the use of genre templates and guides.

Current interactive multimedia technologies can represent ideas in almost any mediated form, and provided we can generate a comprehensible metaphor for organising our functional options and the underlying knowledge structures, the student can roam through the resources creating their own meanings and understandings of the phenomena they encounter. This rich context allows the novice to work with authentic 
problems and practice. As teachers, we have traditionally presented a linear narrative sequence which reveals the underlying structure of our ideas. Aware that the sequence might at times be arbitrary and misleading, we have sought to find alternative ways to structure, represent and unfold relationships between ideas. With graphical and visual display coupled with large databases of resources, it is possible to explore an information space in whatever sequence appeals as appropriate to the task. When raising the idea Florin (1990, p30) saw "information landscapes, ... as virtual towns, or intellectual amusement parks. The analogy is quite intriguing and helps us to visualise many abstract concepts within a single metaphor".

However, within this context designers of multimedia learning environments have tended to be narrow in their view of how users will interact with the rich array of multimedia resources. Instructional designers have not often taken full advantage of the technology that is being used to present these powerful ideas. Once the material has been presented to user(s) and they have interacted in the ways envisaged by the instructional designer (and often in new ways not considered by the designer) the user is left to ponder and present their conclusions using more routine presentation technologies, such as pen and paper. Increasingly, users have access to the same multimedia technology but have lacked access to the rich digital media resources embedded in the learning environment. If students are to truly create their own meanings and understandings of the phenomena they encounter, designers need to incorporate user tools which will allow students to present their findings using the full array of resources contained in the packages. In this paper we will seek to combine the idea of situated cognition with problem solving learning to form the basis for effective design of interactive learning environments. We will review the use of reporting 'notebooks' within these environments supported by cognitive tools such as templates of writing genres. The goal of this discussion is to emphasise the importance in designing supportive environments which employ metacognitive support and which challenge and result in more effective learning outcomes.

\section{Situated Learning and Interactive Multimedia}

When Whitehead (1929) distinguished between 'inert knowledge' and 'robust knowledge' he sought to differentiate between the mass of concepts, principles, and so on, and the learners ability to sift through the elements that are relevant for the task at hand and then to apply them appropriately to achieve a resolution. Information landscapes can provide a useful context for differentiating between these two forms of knowledge. The Cognition and Technology Group at Vanderbilt University (1990) demonstrated in several studies the importance of the "inert knowledge" concept in technology-mediated learning. They talk about "inert knowledge" as knowledge which can usually be recalled which people are 
explicitly asked to do so but which is not used spontaneously in problem solving even though it may be relevant. In one study from members of the group, Bransford et. al. (1990, p132) describe success in getting students to produce their own computer-videodisc presentations using segments from commercially available videodiscs. They give an example of a group of students working on the topic of light who used segments from Star Wars to illustrate some important concepts about light. They concluded that:

\footnotetext{
Although this fact could be read in a science textbook, the use of a very short video segment, tied with text, appears to make the learning of this type of information more meaningful and interesting for students who produced the video and for the other students who watch the productions.
}

Situated cognition has, as its main idea, the notion that "the activity in which knowledge is developed and deployed is not separable from or ancillary to reaming and cognition, but an integral part of what is learned" (Brown, Collins \& Duguid, 1989, p32). The learner's understanding is developed through continuous participation in the ordinary practices of the culture (known as authentic activities) within the community of practitioners, enabling learners to "build an increasingly rich implicit understanding of the world in which they use tools and of the tools themselves". The authentic activities are "framed by the culture. Their meaning and purpose are socially constructed through negotiations among past and present members".

In reviewing a research agenda for interactive multimedia, virtual reality and situated learning, Hedberg and Alexander (1994), have argued that interactive multimedia can provide a useful context for the development of what Lave and Wenger (1991) call legitimate peripheral participation. This participation refers to the engagement of a novice in a socially-based practice in which they can perform the same range of skills as an expert. Interactive multimedia provides an ideal structured environment which allows the novice to work with problems and learning situations which are some "distance" (peripheral) from the core of the expert's world. As the novice begins to practice more as a full practitioner the skills and shared experiences overlap more with those who are acknowledged as expert.

While it is possible for all the elements of an information landscape to appear as unique discrete elements, the sheer volume of resources that the technology allows may appear overwhelming. Often interactive multimedia packages seek only to provide access to a vast array of resources which, if anything, deconstruct knowledge into a series of potentially unrelated and discrete elements. Such information packages do not provide a focus for the systematic development of a novice's skills. Laurillard (1993, p227) claims that "it is possible for new technology to support the more integrative view of knowledge, and the articulation and representation of experience, but this philosophy needs to be built into the design process explicitly, from the beginning." 
Hedberg and Alexander (1994) have identified a number of dimensions which have appeared in the literature to define the growing ability of learning context to provide a sufficient range of legitimate practice. These dimensions might form the basis for the development of appropriate supports for learning from interactive multimedia environments. They include:

Immersion - many authors discuss the concept of immersion and point to it
as the major advantage of the interactive multimedia technology.

Fidelity of representation - educational needs and the resulting use of faithfulness of representation has not received full discussion in the literature.

Active participation - the claim for active participation of the learner who cannot take a passive role in the interaction.

Creating an environment for practice - the crucial features of a traditional method of situated cognition: cognitive apprenticeships.

Each dimension alone does not define the complete range of useful options in learning from information landscapes. For example, immersion has more than the physical sensory dimension to it, its affect on the user is partly a function of the theatrical aspects of the learning experience by computer (Laurel, 1991). There are obviously versions of real world experiences, from complete sets of sensory experiences, olfactory, aurally, visually, tactile, etc, to much more frugal combinations of sound and pictures, which only hint at their real world referents. Thus, the important operating dimensions are not simply immersion or interactivity. It can be argued that many of the recent well designed educational interactive multimedia products, have been designed based upon these more complex and challenging theoretical models.

\section{Problem Solving and Situated Learning}

The aims and expectations of education imply that the process should foster in students the development of transferable, higher order intellectual skills and problem solving skills. They also imply deep and relational learning and the fostering of a positive disposition toward collaborative learning. While various strategies may be employed to foster each of these outcomes, none would seem to encompass the full spectrum more effectively than problem based learning.

It is generally accepted that most people learn best when actively engaged in the learning process. This approach has been the basis of much of modern curriculum development in Science Education and is embedded in our current thinking about learning. A comprehensive overview of active learning has been provided by Bonwell and Eison (1991), with Boud and Feletti (1991) providing compelling evidence supporting the value and efficacy of such processes in classrooms. 
If problem solving strategies are employed through activities in which knowledge is developed and deployed and is not separable from or ancillary to learning and cognition, but an integral part of what is learned, we are working in the realm of situated learning and there will be a potential for enhanced learning to occur.

\section{Multimedia, Literacy and Notetaking}

Our examples are drawn from two multimedia packages which have been developed to allow learners to participate in communities of practice through immersion in authentic activities. The activities are not only visually accurate representations of real world environments, but are also rich in real world data and related information. The packages both presume that novice users, using the package, will attempt to solve problems by mimicking the practices of expert ecologists and environmentalists.

These interactive multimedia CD ROM based packages are called Investigating Lake Iluka and Exploring the Nardoo. Both packages make use of note taking facilities through a simple text based notebook for Investigating Lake Iluka and a sophisticated multimedia notebook for Exploring the Nardoo. The integration of learning strategies, such as note taking, has been reviewed by Kenny and Schroeder (1994), who claim that interactive multimedia systems often include tools for learners to manipulate content, but do not include guidance. This presents a problem since learners frequently do not incorporate structure in their note taking or fail to elaborate on the new information obtained from such sources. Since research has shown that students generally are incomplete note takers (Kiewra, 1987, p88) this may present a serious design flaw that multimedia designers need to consider and overcome. A number of note taking techniques could be incorporated into interactive multimedia programs to enhance student discourse in a more structured fashion. These include linear approaches like outlining (Kiewra et. al., 1991) and spatial learning strategies such as concept maps (Novak and Gowin, 1984).

Programs that use notebooks or notepads have the potential to incorporate the best aspects of note taking, outlining and mapping while avoiding some of their pitfalls. They also have the potential to offer a degree of guidance to users that will encourage users to make use of the full potential of these learning strategies. Kenny and Schroeder (1994) have outlined three capabilities that might be exploited in incorporating learning strategies in a notebook:

- cutting, pasting and manipulating text and media (graphics, sound and video). This could be done in outline or spatial map format using text and / or icons;

- using screen titles and/or topics to organise information and the ability to connect and manipulate these, pull them together into a concept map or hypermap; and

- creating multimedia documents from information gathered. 
The note taking facility in an interactive multimedia package can be extremely flexible. Users can copy information (text, graphics, audio or video) and elaborate and organise as they go along. Alternatively, they can organise the representation of their information after gathering all the data that they need. A notebook that incorporates a range of capabilities will need to offer guidance for the user. The note taking research has demonstrated that users who organise and elaborate on the information collected are more likely to create retrieval cues, link to prior knowledge and make the new information personally relevant.

The student support for note taking and the resulting "solutions to problems" needs to include modelling of the various styles of discourse used in different communities.

Different subjects or curriculum areas may be considered as being different "discourse communities" (Swales, 1990 and Christie, 1991), in which the 'usual members' have the greatest genre specific expertise: that is, networks or communities that work towards a common goal when considering the ways and means by which they communicate with colleagues and others. "It is ... this ... communicative purpose, that drives the language of activities ..., that is the criteria for genre identity ... and ... that operates as the primary determinant of task." (Swales 1990) This is achieved by the adoption of a genre which is highly specific to the discourse community concerned, for example the sciences adopt the highly formal scientific report genre.

Established members of a particular discourse community are familiar and comfortable with the particular 'genre set' characteristic of that discourse community such that they may be termed experts in that genre. 'Outsiders' are novices in this genre and are consequently disempowered to varying degrees and thus cannot communicate as successfully and effectively unless they are either trained and/or supported in the use of the genre being or to be used. Unless we are exposed to and have some practice in the use of the genres used in 'other communities' there may develop a tendency to be limited in our effective communication not only when communicating within our own discourse community, but also when communication is attempted across communities: cross curriculum discourse. The design and implementation of cross curriculum support mechanisms such as the genre templates provided in Exploring the Nardoo can, with appropriate support, provide a means of expanding the boundaries of any one discourse community.

The use of the notebook metaphor can be carried through to the creation of multimedia presentations. The notebook can be used as an organiser for drafting the presentation and should make the transition to a finished multimedia product seamless. Templates such as the genre templates within a notebook can be used as advanced organisers for learners, especially those with little prior knowledge. The templates also provide a 
framework for gathering information and stimulating recall of prior knowledge.

There is ample evidence to support the need to teach the learning strategy of note taking. Students using even simple note taking strategies have difficulty identifying the major concepts and including the appropriate level of detail. Many simply copy verbatim and never elaborate with their own prior knowledge, a proven ineffective strategy. Unless the strategies are understood and implemented correctly, they will be ineffective and probably not used.

\section{Genre and the Development of Literacy}

There is a recognised need for the development of literacy across the curriculum from Kindergarten to Year 12. All faculties need to be aware of the role writing in its many forms plays in the development of literacy, the cognitive support for all learning styles it provides and consequently endeavour to develop strategies which can support this.

Roberts \& Warburton (1991) suggest that computers, literacy and the teaching of genre are inextricably linked. Computers are changing the dimensions of literacy and literacy education is making demands on the technology. The simplest form of this interrelationship manifests itself in the word processor: but word processors alone, without the interaction and support of others, will not teach children to write. They are no more than tools that allow experimentation in language and expression with little negative consequence. They provide a means for the deeper manipulation of text and in conjunction with the genre process can encourage reading, talking and listening. They generate positive attitudes to writing (Nanlohy, 1987), along with interest and motivation and as some would suggest a general improvement in quality. Perhaps their greatest benefit, however, lies in their fostering of creative writing communities, including, of course, the teacher. Writing is an interactive process and the skills developed are supportive of all styles of learning. "Students develop most effectively as writers ... and communicators ... when they learn to write in an active and positive learning environment." (NSW Department of Education, 1987).

One approach to the improvement of literacy suggested by the Literacy and Learning Project, NSW Department of School Education Metropolitan East (1993), is across the curriculum teaching to students of particular writing styles or genres that will provide them with a guide to presenting their ideas in all discourse communities. One might use the word 'presentation' rather than 'writing' to broaden the scope of this approach, since the technology embodied in a delivery system such as that used in Exploring the Nardoo provides the means to go far beyond mere written expression or presentation. There is plenty of indirect evidence for the adoption of such a strategy, however Swales (1990) points out that "hard evidence for the value of genre based approaches to the development of 
communicative competence is not yet readily available". These genres can provide teachers and students alike with text models which are most appropriate for the level of development, preferred learning style and topic being researched. They act as scaffolds, highlighting the structure and stages of information collection, synthesis and presentation and in the long term help the user to become a better learner through the development of information organisation and presentation skills.

Swales (1990) suggests that the term genre has had a number of meanings. An early definition was a distinctive type or category of literary composition and a class of communicative event in which language and para-language play a significant and indispensable role. Currently genre has been defined in a more broad sense as a distinctive category of discourse of any type, spoken or written. One would like to further clarify and modify this by replacing the word category with style and adding the styles oral, aural, visual and perhaps a hybrid form of these, a distinct multimedia style.

As with all information skills, success will only be achieved with immersion and practice. "Engagement in writing extends the range and quality of thinking, feeling and learning." (NSW Department of Education, 1987).

Training in the use and application of genre pivots around:

- students perception of the relevance and value of what they are doing;

- students see the relationships between what they are studying and the genre; and

- students see the success of their efforts.

Modelled writing can be used to teach students about writing processes and different types of text that can be utilised when presenting the results of their investigations and problem solving. Good models will help students understand genres and their role in communication, by highlighting the structures of the communicative process through example and providing a scaffolding on which the student may build.

By encouraging the use of genre templates we are assisting students through a modelled form of outlining. Identifying concepts within their notes that bear some relationship to part of a template structure requires high order thinking skills which "a) causes focusing on important points, b) helps students gain familiarity with text structure, c) aids retention, d) generates useful alternative texts to supplement materials read, and e) causes active participation in learning" (Bianco and McCormick, 1989 in Kenny \& Schroeder, 1994, p966). The value of this modelling process is not faculty, learning style, level of school, or type of writing dependent.

Swales (1990) suggests it is necessary to give students practice and experience with appropriate tasks, since the acquisition of genre skills develops from previous knowledge of the world (giving rise to content 
schemata), and knowledge of prior texts (giving rise to formal schemata) through such experience and practice.

The development by an individual of genre specific schemata can have a number of generative and empowering consequences, most significant of which is the development of the ability to communicate more effectively with a wider spectrum of the community.

\section{Note taking - Investigating Lake Iluka}

The interactive multimedia package Investigating Lake Iluka, which uses a notebook metaphor, was evaluated formatively and summatively to develop the concept of note taking. The notebook in the package is available to the user at any time, and allows the user to compile and edit text, copy text from any textual information embedded in the package, and save the finished compilation to disk as a text file.

The evaluation involved three main approaches: Expert review of the package; one-on-one testing of the prototype materials via video observation and interviews; and in-depth case studies, including the verification of the methods for data analysis of complex multi-path data. The evaluation has been reported in detail in Hedberg and Harper (1995).

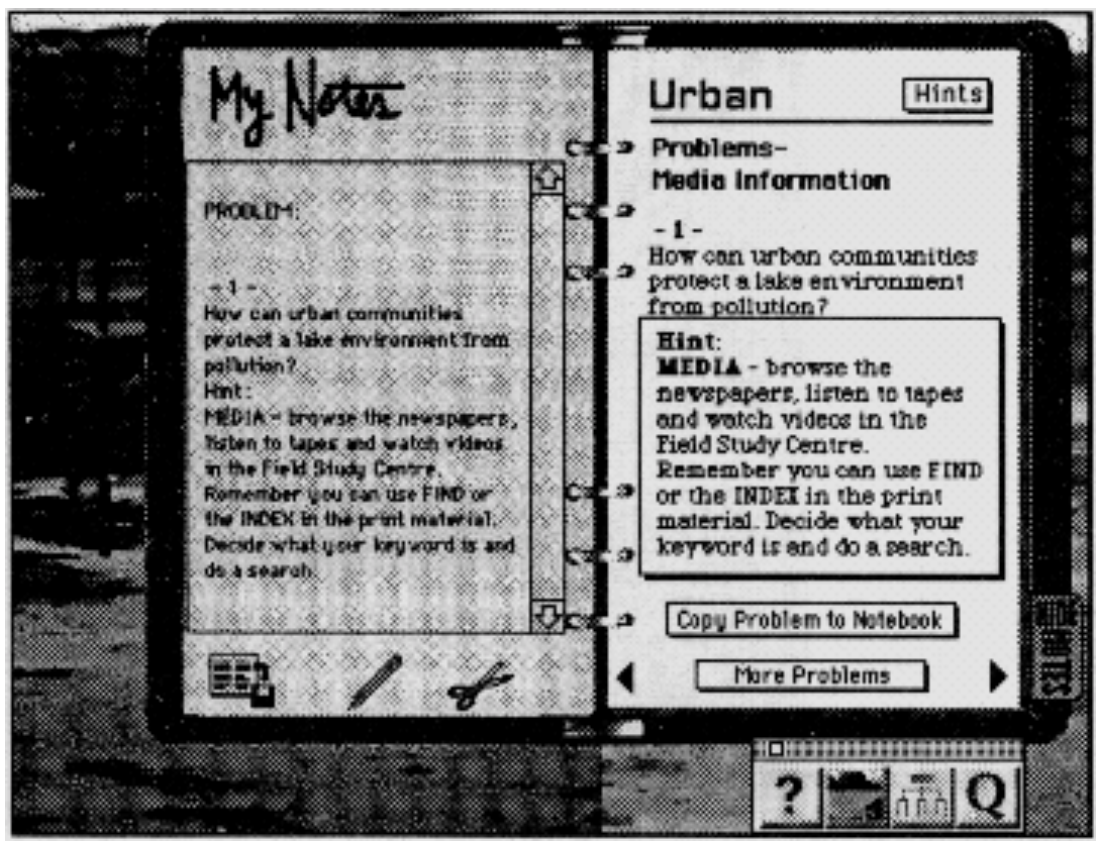

Figure 1: The Text-based notebook metaphor 


\section{The PDA - Exploring the Nardoo}

For note taking, the main drawback of Investigating Lake Iluka has been the reluctance of the students to edit out redundant or unnecessary text in their reports. As a result of the expert and teacher reviews and the observed student use, it was proposed that Exploring the Nardoo should extend the information gathering facilities available to the user through a Personal Digital Assistant (PDA) metaphor. The PDA would have a display element for textual, video, audio and graphic data and "multimedia-based" notes. It could be used to gather, re-organise, edit and view all "multimedia" forms from the information landscape of the package.

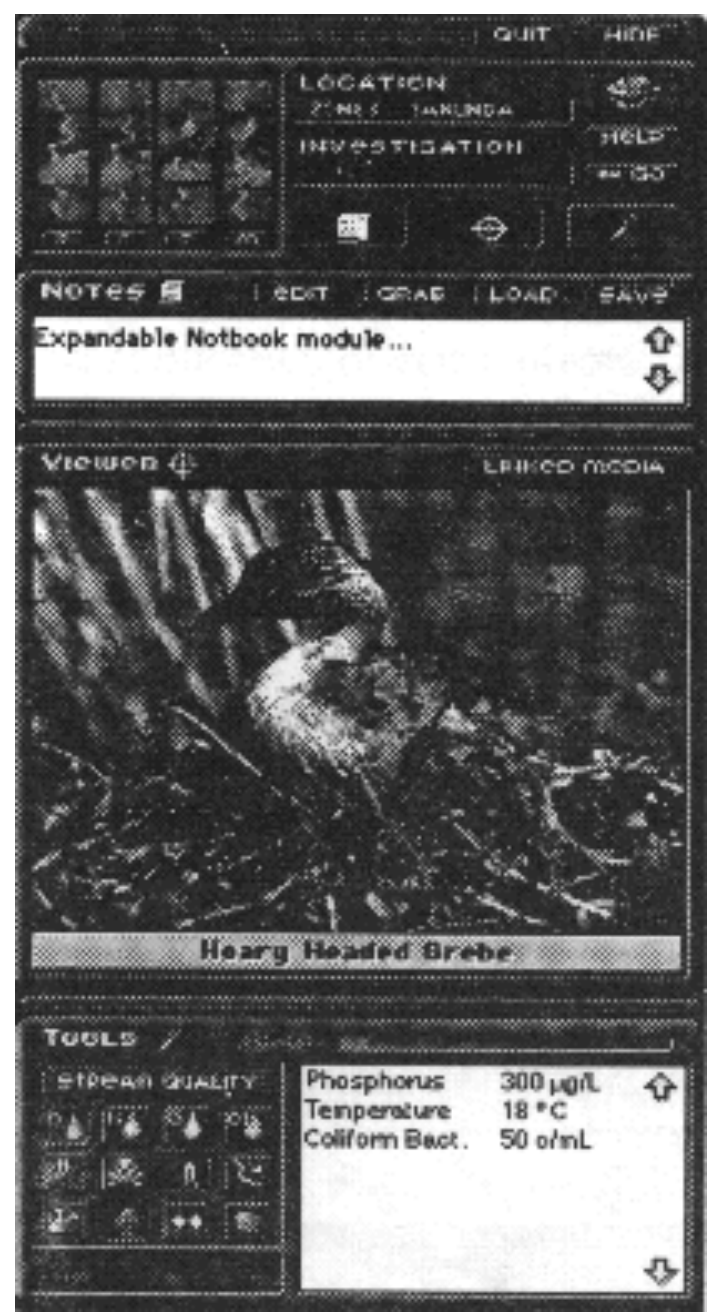

Figure 2: PDA Notebook from Exploring the Nardoo 
The joint combination of notebook and viewer better equips students to view and then critically evaluate or compare different representations of the same information By collecting different media representations of the same topic and 'flipping' between these representations at the their discretion, the student has the opportunity to establish cognitive links between different media forms which compliment each other and support a central theme or information focus.

When examining media reports in the PDA's viewer module the student has the option of placing a 'media button', representative of that particular media item, within their notes. Clicking on this button provides immediate access to the source media item which is displayed within the PDA's viewer. Single media items are able to have multiple elements all accessed by one media button link in the student's notes. For example, placing a media button link to a plant or animal into the viewer not only provides access to related image information but also to a body of text information which can be scrolled, read and copied into their notes if desired.

Like Lake Iluka, Nardoo allows the user to record thoughts and impressions 'on-the-fly' whilst examining media stories. This provides the potential for students to reorganise or revise their thoughts to better 'make sense' of what they see and hear. Students are able to document their emerging ideas in support of an investigation or problem solving exercise whilst viewing different media. This provides support in the formulation of new schemata in the process of accommodating the new information.

By way of illustration, while viewing a video segment related to the issue of water conservation, students may have their attention drawn to a specific aspect such as better ways to manage water use within the household. The Nardoo PDA provides the means by which they are able to search out other related information (text, graphics, radio/television reports) and store it within their notes 'alongside' previously captured information. The different perspectives represented within the source media items can be viewed, edited and brought into context within the student's framework of notes they are making.

To facilitate the re-ordering or re-prioritising of information, Exploring the Nardoo provides a separate, expanded form of the notebook. This device has been termed a 'text tablet'. It provides the editing facilities offered by the PDA as well as other features to assist with the restructuring of notes into a form more suited to small group presentation or a particular genre style. The text tablet provides a larger expanse of editable screen/document space into which student notes may be copied to/from the PDA notes module.

A writing genre template (discussed in the following section) can also be loaded directly into the text tablet into which portions of the student's notes may be copied or dragged. Notes from prior sessions can be loaded 
into the text tablet and used in support of current investigations. Being able to store and report thoughts and impressions derived from media experiences by using of the media itself (actual video/audio and pictures, not just text representations of the media) provides a more powerful means of 'reformulating' (Schroeder \& Kenny, 1994, p 965) ideas.

As Kenny and Schroeder (1994) point out "learners not accustomed to this technique and multimedia facilities will require instruction in its use" before they become proficient with the technique but once accustomed to it the student has a powerful process at their disposal to gather, organise and illustrate their ideas. Support for teachers and students in the use of these features will be modelled through walk-through movies made available through the help system and also detailed in support notes available in reference books within the package.

\section{Using the Genre Templates}

The genre templates provided in Exploring the Nardoo include Report, Explanation, Procedure, Exposition, Discussion, Narrative, Recount, and Review. These templates are not meant to be prescriptive, rather it must be stressed that their most effective use may involve the blending of one or more.

Of significant importance in this package is the development of a 'new genre', born of computers and their associated technologies: the multimedia genre. Such a genre may be considered as the expression of what Swales (1990) terms "para-language" in a communicative event and manifests itself as a melding of all methods of communication, written, oral, visual and aural.

Swales (1990) says that "...there is an affinity between the situational approach and the learning of the use of language". In the Nardoo, there is a media rich interactive environment with supportive scaffolds (the knowledge landscapes, templates and the text tablet) for both the preparation and presentation of materials that allow students to practice situation-specific skills based on authentic activities. In theory, this will support the students' learning of the use of language. However, Wilkins (1973) and others have suggested that this approach could be seen as being rather superficial and, in the long term, produce only a parody of real language usage learning.

The essential aim of the templates in Exploring the Nardoo is, through the modelling of the different genres and the provision of scaffolds on which the students can build, to help students learn to use the different genre specific to, and characteristic of, the various discourse communities. The package is therefore automatically strongly cross-curriculum linked. The templates provide cognitive support for problem solving and the development of other higher-order cognitive skills by giving students 
frameworks that will concentrate thought, facilitate investigation, and develop critical and creative thinking They will provide a valuable training ground for demonstration and immersion in the use of genres, and the fostering of student responsibility in the development of presentation skills.

They will also provide a means of composing meaning for both the writer and the reader/listener while at the same time provide a means of reflection, re-ordering and creating new learning nodes and links between new and prior knowledge The production of an effective piece of writing or presentation in any media can provide the student with a means of consolidating these links. It can also enhance the students confidence, self esteem and motivation to stay on and complete a task. The availability of a range of genre templates with added character-guide or text-based support embodies the notion of providing "strategies that help them encode the information they encounter" suggested by Schroeder \& Kenny (1994, p963).

The PDA allows the user to place a genre template within the Notes module as an organising tool from the outset of an investigation exercise or, if they wish, it can be used after collecting a range of information and data which can be reorganised by cut and paste or drag and drop mechanisms within the notes module. For many students the actual collection of materials before writing is a difficult process in itself. Students with poor reading and research skills can be disadvantaged in this process and hence the careful and guided use of such supportive structures as the genre templates being incorporated in Exploring the Nardoo will provide invaluable support for these students, reducing the amount of reading, lowering the cognitive load and orientating the work more towards student-centred learning.

One cannot stress too heavily the need for teacher support in the use of such supportive structures. Only when the student has a thorough knowledge of how a genre 'ticks' will it be fully understood and used most effectively. "Teachers need to overtly model the textural features of the genre, to provide feedback" (Roberts \& Warburton, 1991) as they (students and teachers) learn to use the genre. The technology utilised in the way it is in Exploring the Nardoo can make the task more effective for both teacher and student. "Genre as instruments of ... communication ... can have generative power" (Swales, 1990). They can provide the means for mapping and exploring new territories, but the empowerment must be tempered with practice, reflection and (teacher) support.

\section{Conclusion}

Investigating Lake Iluka broke new ground in providing a supportive notebook to allow the student to collect and report their investigation based on problem solving techniques. Exploring the Nardoo has extended 
this concept to incorporate multimedia tools for reporting supported by several metacognitive tools for the writing process. These tools not only include details about genre but also templates to support the learners. The evaluation process is currently underway. The major focus is upon the ways in which students can manipulate the tools and also extend common concepts such as copy and paste into other forms of representation of information.

\section{References}

Bonwell, C. J. and Eison, J. (1991). Active Learning: Creating Excitement in the Classroom. ASHE-ERIC Higher Education Report No.1, Washington DC: The George Washington University.

Boud, D. and Feletti, G. (Ed) (1991). The Challenge for Problem Based Learning, London: Kogan Page.

Bransford, J. D., Sherwood, R. D., Hasselbring, T. S., Kinzer, C. K. and Williams, S. M. (1990). Anchored Instruction: Why we need it and how technology can help. In Nix, D. and Spiro, R., Cognition, Education, Multimedia: Exploring Ideas in High Technology. Lawrence Erlbaum Associates, Hillsdale, Publishers.

Brown, J. S., Collins, A. \& Duguid, P (1989). Situated Cognition and the Culture of Learning, Educational Researcher, 18(1), 32-41.

Christie, F. (1991). Genre and Curriculum. Genre Approaches to Literacy: Theories and Practices. Cope, B \& Kalantzis, M. (eds), 1991 LERN Conference, University of Technology, Sydney. pp 3 -15

Cognition and Technology Group at Vanderbilt (1990). Anchored Instruction and its relationship to situated cognition. Educational Researcher, 19(6), 2-10.

Florin, F. (1990). Information Landscapes. In S. Ambron, \& K. Hooper (Eds), Learning with Interactive Multimedia. Redmond: Microsoft. pp 28-49.

Hedberg, J. G. \& Alexander, S. (1994). Virtual Reality in Education: Defining Researchable Issues. Educational Media International, 31(4), 214-220.

Hedberg, John G. \& Harper, Barry (1995). Exploring Interactive Multimedia Information Landscapes. Educational Multimedia and Hypermedia, Proceedings of ED-MEDIA 95 World Conference on Educational Multimedia and Hypermedia, Graz, Austria; June 17-21, pp. 301-305.

Kenny, R., \& Schroeder, E. (1994). The Integration of Learning Strategies in Interactive Multimedia Instruction, Paper presented at the AECT National Convention and INCITE'94 International Exposition, Nashville, TN, February 961-979.

Kiewra, K. A. (1987). Note taking and review: The research and its implications. Instructional Science, 16, 233-249.

Kiewra, K. A., Mayer, R. E., Christensen, M., Kim, S. \& Risch, N. (1991). Effects of repetition on recall and note taking: Strategies for learning from lectures. Journal of Educational Psychology, 33(1),120-123.

Laurel, B. (1991). Computers as Theatre. Reading, MA: Addison-Wesley.

Laurillard, D. (1993). Rethinking University Teaching: A framework for the effective use of educational technology. London: Routledge.

Lave, J. and Wenger, E. (1991). Situated Learning: Legitimate Peripheral Practice. Cambridge: Cambridge University Press.

Nanlohy, P (1987). Writing with Computers - Process and Genre-based Writing: Doing something You've Never Done Before. Proceedings of the 5th Annual Conference of the New South Wales Computer Education Group. Mitchell College Printery. Bathurst. pp 155-165. 
Novak, J. D. \& Gowin, D. B. (1984). Learning how to learn. New York: Cambridge University Press.

Roberts, P. \& Warburton, M. (1991). Computers and Genre in Social Science. Genre Approaches to Literacy: Theories and Practices. Cope, B. \& Kalantzis, M. (eds), 1991 LERN Conference, University of Technology, Sydney. pp 283-289.

Swales, J. M. (1990). Genre Analysis: English in Academic and Research Settings. The Cambridge Applied Linguistics Series. Long, M. H. and Richards, J. C. (eds). Cambridge University Press. Sydney.

Whitehead, A. N. (1929). The Aims of Education. New York: Macmillan.

Wilkins, D. (1973). Grammatical, situational and National Syllabuses. ELT Documents, 73(6), 2-8.

Please cite as: Harper, B. M., Hedberg, J. G., Wright, R. J. and Corderoy, R. M. (1995). Multimedia reporting in science problem solving. Australian Journal of Educational Technology, 11(2), 23-37.

http:/ / www.ascilite.org.au/ajet/ajet11/harper.html 